Historic, archived document

Do not assume content reflects current scientific knowledge, policies, or practices. 



\section{9 \\ SURDEERARTMENT OF AGRICULTURE}

\section{PACIFIC SOUTHWEST FOREST AND RANGE EXPERIMENT Station BERKELEY - CALIFORNIA}

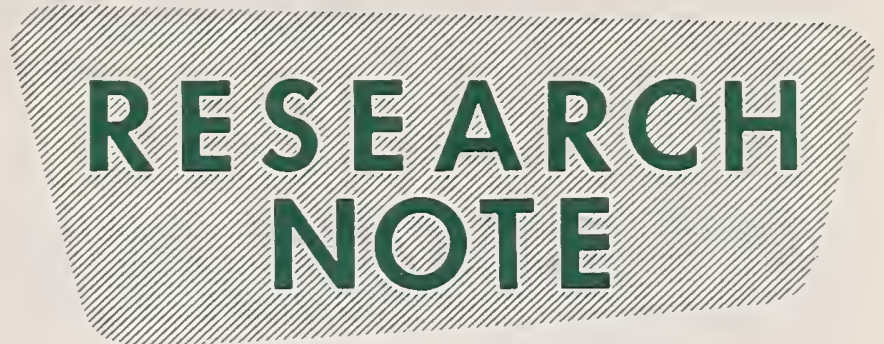

Apri1 1961

No. 178

GIBBERELIIN AND THIOUREA BREAK SEED DORMANCY

IN CALIFORNIA CEANOTHUS

Lowell Adams, Wildlife Research Biologist

Eugene Stefanescu, Range Aid (Research)

David J. Dunaway, Range Aid (Research)

Division of Range Management and

Wildlife Habitat Research

Seeds of most wild shrubs do not germinate until they are "winterized" naturally or by artificial treatment. Consequently, seeding of shrubs for game range improvement is nearly always faced with this immediate handicap. One of the most common methods of breaking seed dormancy is stratification in cold moist sand. This takes up to three months, however, and the seeds must be kept moist thereafter until planted. These requirements present cumbersome limitations in large-scale, practical seedings. In recent years considerable progress has been made in breaking dormancy with chemicals.

This report describes a newly-discovered chemical treatment for breaking seed dormancy in three species of Ceanothus: mountain whitethorn (c. cordulatus Kell.), Lemmons ceanothus (C. lemmonii Parry), and buckbrush ceanothus ( $\underline{\text { c. cuneatus }}$ (Hook)). The chemicals used are gibberellin and thiourea.

The treatment that increased germination most consisted of:

(1). Soaking seeds in boiling water one minute,

(2) Soaking in gibberellin (400 parts per million) 13 hours,

(3) Drying the seeds 4 days, and

(4) Soaking in 3 percent thiourea five minutes to one hour.

Variations in soaking times and chemical concentrations gave graded responses less effective than the above procedure. 
A variety of treatments was applied to four other species without success:

\section{Species}

Bigberry manzanita (Arctostaphylos slauca Lindl. $\longdiv { \text { and } }$ bittercherry (Prunus emarginata (Dougl.) Walp.)

Deerbrush (Ceanothus integerrimus H. \& A.) and Fremont silktassel (Garrya Fremontii Torr.)

\section{Treatments}

Same gibberellin-thiourea treatments given successfully to the three ceanothus species.

A great variety including various combinations and levels of hot water, thiourea, Eibberellin, heat, cold and light.

These species and treatments are not included in the following description of the successful experiments, but information will be supplied upon inquiry to the authors.

\section{The Experiments and Results}

We submitted the seeds of the three species of ceanothus first to treatments for dormancy attributable to the seed coat, and second to treatments for dormancy in the seed itself.

Seed-coat Treatments

A seed lot from each species was immersed in each of the following chemicals that have been used by others to make seed coats permeable:

Chemical.

sodium irypochlorite

acetone

$\mathrm{xylol}$

methyl alcohol

ether

sulfuric acid

hot water $\frac{\text { Concentration }}{\text { (Percent) }}$

5.25

100.00

100.00

95.00

100.00

cone. $\frac{\text { Soaking Time }}{\text { (Hours })}$

$1 / 2,2,5,24$

$1 / 2,2,5,24$

$1 / 2,2,5,24$

$1 / 2,2,5,24$

$1 / 2,2,5,24$

$1 / 2, \quad 11 / 2,21 / 2$

steep or boil I]

If Steep: seeds placed in one liter of water at $180^{\circ} \mathrm{F}$. and allowed to cool to room temperature. Boil: seeds immersed in boiling water 1 , 4 or 3 minutes.

The test of effectiveness of seed-coat treatments was whether the treated seeds plumped (imbibed water) after treatment when placed on wet blotting paper in petri dishes. One set of untreated seeds was placed in germination dislies as controls. 
The seeds of all three ceanothus species plumped after all treatments at all levels. With no treatment, a small percentage of the buckbrush seeds, but no others, plumped.

\title{
Seed Treatments
}

Since all seed-coat treatments resulted in plumping in ceanothus, we used the simplest treatment--boiling for one minute--to induce seedcoat permeability before seed treatment. Then seeds were immersed 13 hours in gibberellin (gibberellic acid neutralized with potassium hydroxide) at three concentrations: 200, 400, and 800 parts per million. A fourth lot of seeds received no gibberellin treatment.

After drying for 4 days, each lot of gibberellin-treated seed, plus an untreated lot, was immersed in 3 percent thiourea for 5 minutes and for 1, 24, and 72 hours. Thus, individual lots of the seeds of each species of shrub were subjected to one of 16 treatments (fig. 1 ).

Thiourea without gibberellin had practically no effect except in buckbrush, where we achieved about the same results as Hubbard I/ who used similar treatment. The gibberellin more than doubled the germination rate over the treatment with thiourea alone.

We found no deformed seedlings such as McConnell $2 /$ reported in gibberellic acid-treated bitterbrush.

Since varietal or strain differences may affect response to dormancy treatments, the sources of seeds we used are listed below. All are from California.

\author{
Manzanita - Paradise, Butte County \\ Cherry - Snag Lake, Butte County \\ Deerbrush - "Southern California" \\ Mountain whitethorn - Yellow Creek, Plumas County \\ Lemons ceanothus - Magalia, Butte County \\ Buckbrush, Paradise, Butte County \\ Silktassel - "Near Paradise"
}

All seeds were purchased from commercial seed sources and were tested within 1 year after purchase.

1 Hubbard, Richard L. Hot water bath and thiourea break dormancy of wedgeleaf ceanothus seed. U. S. Forest Serv. Calif. Forest and Range Expt. Sta. Res. Note 143. 4 pp. 1958.

2) McConnell, Burt R. Effect of gibberellic acid and cold treatments on the germination of bitterbrush seed. U. S. Forest Serv. Pacific Northwest Forest and Range Expt. Sta. Res. Note 187. 4 pp. 1960. 

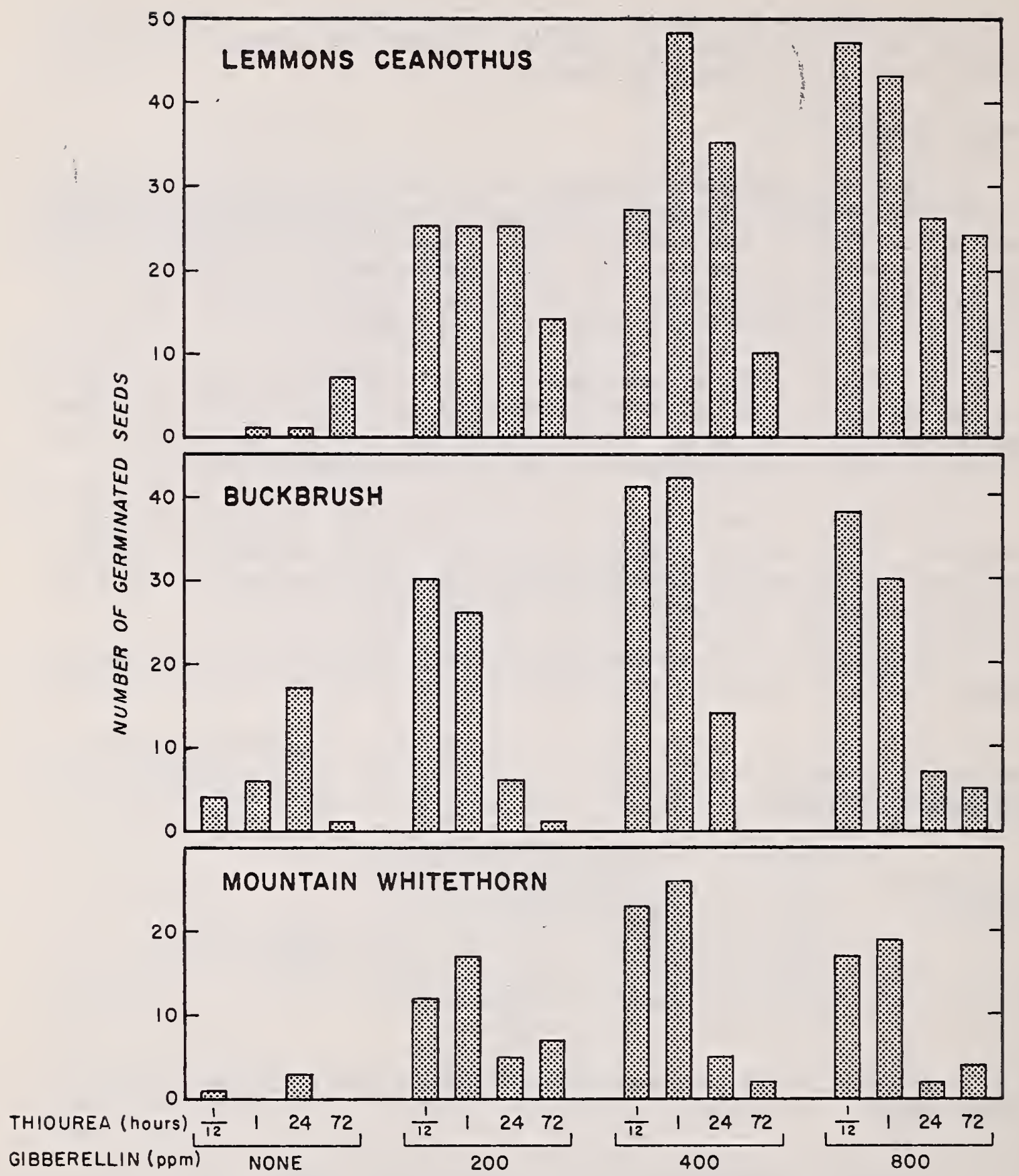

Figure 1.--Numbers of seeds germinated in 50-seed lots treated with four levels of gibberellin and four of thiourea. 

